TITLE:

\title{
Anisotropic thermal conductivity of three-layer laminated carbon- graphite composites from carbonized wood
}

\section{$\operatorname{AUTHOR(S):~}$}

Sulistyo, Joko; Hata, Toshimitsu; Fujisawa, Masashi; Hashimoto, Kozo; Imamura, Yuji; Kawasaki, Tamami

\section{CITATION:}

Sulistyo, Joko ... [et al]. Anisotropic thermal conductivity of three-layer laminated carbongraphite composites from carbonized wood. Journal of Materials Science 2009, 44(3): 734744

\section{ISSUE DATE:}

2009-02

URL:

http://hdl.handle.net/2433/85224

\section{RIGHT:}

The original publication is available at www.springerlink.com; This is not the published version. Please cite only the published version.; この 論文は出版社版でありません。引用の際には出版社版をご確認ご利用 ください。 


\section{Anisotropic Thermal Conductivity of Three-layer Laminated Carbon-Graphite Composites from Carbonized Wood}

Joko Sulistyo, Toshimitsu Hata, Masashi Fujisawa, Kozo Hashimoto, Yuji Imamura, Tamami Kawasaki

Authors:

Joko Sulistyo, Toshimitsu Hata, Yuji Imamura, Tamami Kawasaki

Laboratory of Innovative Humano-habitability - Research Institute for Sustainable Humanosphere, Kyoto

University, Uji Campus, Gokasho, Uji, Kyoto, 611-0011, Japan

Masashi Fujisawa

Institute of Wood Technology, Akita Prefectural University, 11-1 Kaieizaka Nosiro, Akita 016-0876, Japan

Kozo Hashimoto

Laboratory of Applied Radio Engineering for Humanosphere- Research Institute for Sustainable

Humanosphere, Kyoto University, Uji Campus, Gokasho, Uji, Kyoto, 611-0011, Japan

Corresponding author:

Toshimitsu Hata

Email: hata@rish.kyoto-u.ac.jp

\section{Abstract}

Composites with characteristics of anisotropic thermal conductivity for thermal management in Solar Power Satellite (SPS), to discharge the heat that was generated when solar energy was not converted to electricity were developed by alternating layers of laminated graphite and carbonized wood. The effects of the weight fraction of carbonized wood, particle size, interlayer interfaces, and environment temperature on the thermal conductivity and the ratio of thermal conductivity between horizontal and vertical directions ( $\mathrm{H} / \mathrm{V}$ ratio) to the plain surface of samples were discussed. The thermal conductivities of carbon-graphite $(\mathrm{C} / \mathrm{G})$ composites were measured using the laser flash method. Laminated $\mathrm{C} / \mathrm{G}$ composites improved the anisotropic thermal conductivity. The highest H/V ratio of 10.17 was obtained at $10 \mathrm{wt} \%$ of carbonized wood. Particle size and interlayer interfaces were found to affect the anisotropic thermal conductivity. The thermal conductivity of $\mathrm{C} / \mathrm{G}$ composites increased with increasing temperature from $25^{\circ} \mathrm{C}$ to $150{ }^{\circ} \mathrm{C}$.

\section{Introduction}

Thermal management is a key factor in the design of SPS systems. This application is required 
to release heat from solar panels and microwave power transmitters in an SPS. The heat is generated when solar energy is not converted to electricity. The development of lightweight thermal conductive materials that exhibit a controlled heat flow direction is necessary in order to achieve efficient heat release. In the SPS, the thermal conductive material will transfer the heat from the sources to enable the heat through the horizontal conduction to fins or radiators for heat dissipation.

Graphite is a potential material for this application because it meets the requirements and has an excellent thermal shock resistance and anisotropic thermal conductivity [1-4]. The anisotropic characteristics are a result of the graphite structure that has carbon layers with covalent bonding within each layer and van der Waals forces between the layers [3]. Pyrolytic graphite with well-oriented graphite crystals has shown high ratios of thermal conductivity between the horizontal and vertical directions (H/V ratio) [5-6] to the plane surface of samples. In contrast, poorly oriented natural graphite has a low anisotropy of thermal conductivity, as revealed by H/V ratios ranging from 3 to 6 [5]. Treatments at high temperatures of up to $3,000{ }^{\circ} \mathrm{C}$ and high pressure only improved the thermal conductivity of graphite but had no effect on the $\mathrm{H} / \mathrm{V}$ ratio [7-8]. The treatments influence the increase in preferred orientation of crystallites and the growth of crystallite dimensions in the molecular scale. However, in the macro scale of graphite samples, there is no orientation of crystallite.

In this study, the anisotropic materials for thermal management in SPS for achieving the heat reduction were developed through a series of alternate layers of natural graphite and carbonized wood. The lamination of carbonized wood, a material with disordered carbon crystallites [9], between graphite has been used to orient graphite on the macro scale. Until now, there has been no study on the lamination of two carbon materials with different degrees of ordered carbon crystallites to improve the anisotropic thermal conductivity of a composite material. A simple heat treatment at $700{ }^{\circ} \mathrm{C}$ under high pressure was used to prepare the carbon-graphite $(\mathrm{C} / \mathrm{G})$ composites. The temperature of $700{ }^{\circ} \mathrm{C}$ was applied because around this point, carbonized wood is changed from an isolator to a conductor material [10-11]. Therefore, less energy is needed in the preparation of this composite.

The development of this material opens the possibility of utilizing carbonized wood for thermal management applications. The objective of this study is to examine of the anisotropic thermal conductivity of $\mathrm{C} / \mathrm{G}$ composites using the laser flash method. The effects of weight fraction of carbonized wood, particle size, and interlayer interface were investigated. The thermal conductivity of $\mathrm{C} / \mathrm{G}$ 
composites was also measured at temperatures ranging from $25{ }^{\circ} \mathrm{C}$ to $150{ }^{\circ} \mathrm{C}$ under vacuum conditions, because the SPS will be used in space. In addition, scanning electron microscope (SEM) observations were performed to analyze the relationship between the morphology of the composites and the thermal conductivities. Raman spectroscopy was performed to analyze the structure of carbonized wood and graphite during the heat treatment.

\section{Experimental}

\subsection{Carbonization}

Sugi wood (Cryptomerial japonica) particles were carbonized at a heating rate of $4{ }^{\circ} \mathrm{C} / \mathrm{min}$ and were then maintained constant at a temperature of $700{ }^{\circ} \mathrm{C}$ for $1 \mathrm{~h}$ in Argon gas flowing at a rate of 100 $\mathrm{mL} / \mathrm{min}$ in a laboratory scale electric furnace. Small flakes of $2-3 \mathrm{~mm}$ were shaved from commercial graphite rods (PITT Pure Graphite 2900 6B Faber-Castell, diameter: $7 \mathrm{~mm}$, length: $175 \mathrm{~mm}$ ). Both carbonized wood particles and graphite flakes were granulated using a vibration mill and sieved with wire mesh screens of $25,32,45,63$, and $90 \mu \mathrm{m}$ apertures to obtain ranges of $25-32,32-45$, and $63-90 \mu \mathrm{m}$, which were oven dried for $24 \mathrm{~h}$.

\subsection{Heat treatment}

A dry weight of $1 \mathrm{~g}$ of the materials was used to prepare samples with a diameter of $30 \mathrm{~mm}$, and a dry weight of $0.08 \mathrm{~g}$ of the materials was used to prepare samples with a diameter of $10 \mathrm{~mm}$. Three-layer $\mathrm{C} / \mathrm{G}$ composites were prepared by placing the powder into a graphite die to obtain a series of alternating layers of graphite and carbonized wood. Single layer composites (SL) of graphite (G100) and carbonized wood $(\mathrm{C} 100)$ were also prepared. The powder in the die was then heated to $700{ }^{\circ} \mathrm{C}$ at a rate of approximately $71{ }^{\circ} \mathrm{C} / \mathrm{min}$, with a holding time of $15 \mathrm{~min}$ under vacuum conditions using a pulse current sintering apparatus (VCSP-II). A pressure of $50 \mathrm{MPa}$ was applied from the start of the heating and was released immediately after the reaction.

To evaluate the effect of the weight fraction of carbonized wood, three-layer laminated samples containing carbonized wood from $0 \mathrm{wt} \%$ to $100 \mathrm{wt} \%$ were prepared using particles of sizes $25-32,32-45$, and $63-90 \mu \mathrm{m}$. To evaluate the effect of interlayer interfaces, samples with $10 \mathrm{wt} \%$ of carbonized wood $(\mathrm{C} / \mathrm{G}=10 / 90)$ using particles of size $25-32 \mu \mathrm{m}$ were formed into multilayer composites with $2,3,5,7$, and 9 layers. 


\subsection{Characterization}

\subsubsection{Density and morphology}

The density of the composites was determined from their mass and volume as measured using a digital microbalance and a micrometer, respectively. The layer thicknesses of graphite and carbonized wood were measured at five positions on the samples using an optical microscope equipped with a special measurement software package called CamView. The density and layer thickness of $\mathrm{C} / \mathrm{G}$ composites are shown in Table 1. Scanning electron microscope (JEOL JSM 5310, Japan) observations were conducted in order to analyze the morphology of the graphite layer, the carbonized wood layer, and the interlayer interface area between the graphite and carbonized wood layers in the $\mathrm{C} / \mathrm{G}$ composites using three particle sizes.

\subsubsection{Raman spectroscopy}

A Raman spectroscope (Renishaw inVia, England) equipped with an air-cooled CCD detector was used to analyze the carbon structure of carbonized wood and graphite before and after the heat treatment process. An argon laser $(514.5 \mathrm{~nm})$ was adopted as an excitation source. The laser was focused to approximately $1 \mu \mathrm{m}$ in diameter at a power of less than $1 \mathrm{~mW}$ on the sample surface in order to prevent irreversible thermal degradation. Spectra were measured in the $1,100-1,800 \mathrm{~cm}^{-1}$ range. Six $30-\mathrm{s}$ accumulations gave adequate signal-to-noise ratio of the spectra. The wave number was calibrated using the $520 \mathrm{~cm}^{-1}$ line of a silicon wafer. Spectral processing was performed using WiRE 2 software.

\subsubsection{Thermal conductivity}

The specific heat capacity and the thermal diffusivity of the specimens were measured by a laser-flash method using a thermal-constant analyzer (Ulvac Shinku-Riko TC-7000H, Japan). A short pulse of heat was applied to the front face of each specimen, and the thermal diffusivity was calculated from the temperature profile of the unexposed surface [12]. To observe the anisotropy characteristics of $\mathrm{C} / \mathrm{G}$ composites, thermal diffusivity was measured in the horizontal and vertical directions to the plane surfaces of the samples at room temperature. Measurements of thermal diffusivity in the vertical direction were also performed at temperatures from $25{ }^{\circ} \mathrm{C}$ to $150{ }^{\circ} \mathrm{C}$ in air and under vacuum conditions. The thermal diffusivity was calculated as 
$\alpha=\frac{0.1388 d^{2}}{t_{1 / 2}}$

where $d$ is the thickness of the specimen and $t_{1 / 2}$ is the time required for the temperature of the rear face to increase to one-half of the maximum temperature. The specific heat capacity was calculated as

$$
C=\frac{Q}{d \rho \Delta T_{0}}
$$

where $Q$ is the absorbed quantity of heat, $d$ is the thickness of the test piece, $\rho$ is the density of the test piece, and $\Delta T_{0}$ is the extrapolated temperature increase. The thermal conductivity was calculated using the following equation:

$$
k=\rho C \alpha
$$

where $\rho$ is the bulk density, $C$ is the specific thermal capacity, and $\alpha$ is the thermal diffusivity.

\section{Results and Discussion}

\subsection{Morphology}

Figures 1a-f illustrates cross sectional images of three-layer laminated $\mathrm{C} / \mathrm{G}$ composites obtained using an optical microscope. Due to the different light reflection behaviors, the layers of graphite and carbonized wood could be distinguished easily, because in the case of the graphite layer, the surface appeared to be brighter than in the carbonized wood layer. The presence of the carbonized wood layer resulted in the alignment of graphite layers in the horizontal direction to the plain surface of samples with quite clear interlayer interfaces. Due to the density differences, the layer thickness of graphite and the carbonized wood on sample $\mathrm{C} / \mathrm{G}=33 / 67$ having a similar weight fraction were significantly different, as shown in Fig. 1c.

Figures 2a-b shows SEM images of carbonized wood and graphite particles of size $63-90 \mu \mathrm{m}$. The carbonized wood particle maintained the cellular structures as in the original wood. Lumens aligned parallel to the length of particle did still exist (point $A$ in Fig. 2a). The agglomerated particle of graphite, which is different from those in previous articles [13, 14], consisted of fine particles of size 10-20 $\mu \mathrm{m}$ and voids, as shown by points $B$ and $C$ in Fig. $2 \mathrm{~b}$. The particle interface between the fine particles $(D)$ was also observed.

Figures $2 \mathrm{c}-\mathrm{d}$ shows cross-sectional images of the carbonized wood layer with particle sizes of 25-32 and 63-90 $\mu \mathrm{m}$. The SEM images show that the particles on area $E$ were closely packed 
perpendicularly (parallel bars) to the pressure direction (vertical arrows) during the heat treatment under a pressure of $50 \mathrm{MPa}$. As a result of the pressure during the heat treatment, particles and voids tended to be oriented parallel to the plain surface of the samples (point $C$ and area $E$ in Fig. 2c-d). The cellular structures (area $E$ ) of the particles of size 63-90 $\mu \mathrm{m}$ oriented in the horizontal direction were broken. On the other hand, few particles having an angle of approximately $45^{\circ}$ to the pressure direction were broken (area $F$ in Fig. 2d). Lumens and voids (points $A$ and $C$ ) on these areas ( $E$ and $F$ ) were aligned similar to the particles orientation.

Figure 2e shows an SEM image of the top surface of the graphite layer. The graphite particles were observed to be compacted. However, small voids appeared after heat treatment at a pressure of 50 MPa (point C in Fig. 2e). The morphology of the graphite layer in this study, which is similar to the specimens subjected to heat treatment at $1,800{ }^{\circ} \mathrm{C}$ and a pressure of $40 \mathrm{MPa}$ [15], is more compact than that of the carbonized wood layer, as shown in Fig. 2(f). Figure 2(f) also shows a rough interlayer interface between the graphite and carbonized wood layers.

\subsection{Thermal conductivity}

\subsubsection{Single-layer composite of graphite and carbonized wood}

The values of thermal conductivity and H/V ratio of single-layer composite (SL) of graphite (G100) and carbonized wood (C100) are presented in Table 2. The SL of graphite had greater thermal conductivity than that of the SL carbonized wood. The thermal conductivity increased in the case of SL carbonized wood but decreased in the case of SL graphite in both the horizontal and vertical directions to the plain surface of sample with the increase of particle size. As the particle size increases, lower discontinuity occurs more frequently. Consequently, the heat flows faster in the case of larger particles than in the case of smaller particles. The increase in thermal conductivity with increasing particle size was reported in previous studies on graphite flake composites and molded carbon phenolic spheres $[7,16]$. In the case of SL graphite, it has been suggested that decrease in thermal conductivity occurs due to the effect of agglomerated graphite particles [17], as shown in Fig. 2b. The agglomerated particle of graphite introduced voids and particle interfaces that may reduce the thermal conductivity, as shown by points $C$ and $D$ in Fig. 2b. With the increase of agglomerated particle size, the interface area of fine particles is considered to be more extensive.

Single layer composites of both graphite and carbonized wood showed anisotropic thermal 
conductivity. The H/V ratios of SL graphite, which are similar to those in a previous study on natural graphite [5], were 2-4 times higher than that of SL carbonized wood. The H/V ratios in the range from 3.63 to 4.46 indicate poorly oriented carbon crystallite in the bulk samples of SL graphite, as shown in Fig. 3. Particle size had no effect on the $\mathrm{H} / \mathrm{V}$ ratio in the SL graphite samples. In the case of SL carbonized wood, the H/V ratios were close to those of solid wood [18]. The reason for this is thought to be related to the orientation of particles and voids in the horizontal direction to the plain surface of sample, as shown by area $E$ in Figs. 2c-d. However, in a particle of carbonized wood the heat flows uniformly in all directions due to the homogenous distribution of carbon crystallite in the cell wall of wood carbonized at $700{ }^{\circ} \mathrm{C}$, as reported by Ishimaru [9]. However, because of the influence of porosity and voids on the thermal conductivity $[19,20]$, the heat flow becomes faster within particles in the horizontal direction, as compared to that across the voids in the vertical direction with the $\mathrm{H} / \mathrm{V}$ ratio in the range of 1.65 to 2.31 . The H/V ratio in SL carbonized wood decreased with the increase of particle size. The SEM image revealed that carbonized wood particles of $63-90 \mu \mathrm{m}$, including lumens and voids, were oriented in the horizontal direction and in the direction at an angle of approximately $45^{\circ}$ to the plain surface of sample, as shown by areas E and F in Fig. 2d. Therefore, with the increase of particle size, the heat flow in the vertical direction increased more significantly than that in the horizontal direction, resulting on the decrease in the $\mathrm{H} / \mathrm{V}$ ratio in SL carbonized wood.

\subsubsection{Three-layer laminated $C / G$ composites}

Figure 3 illustrates the schematic structure of three-layer laminated $\mathrm{C} / \mathrm{G}$ composites, which consists of graphite layers for both surfaces and carbonized wood in the core layer. The $\mathrm{C} / \mathrm{G}$ composites were constructed of alternate layering of materials that had highly ordered and turbostratic/disordered microstructures. Although on the molecular scale graphite has a highly ordered structure, carbon crystallites were estimated to be oriented randomly in a graphite layer. Laminated composites consisting of alternate layers of graphite and carbonized wood provide horizontally aligned graphite layers in the macro scale of $\mathrm{C} / \mathrm{G}$ composites.

Figure $4 \mathrm{a}$ shows the effect of the weight fraction of carbonized wood on the thermal conductivity of $\mathrm{C} / \mathrm{G}$ composites using particle sizes of $25-32,32-45$, and $63-90 \mu \mathrm{m}$. The presence of a carbonized wood layer with a disordered microstructure and a porous structure accounts for the decrease in magnitude of the thermal conductivity being different in the horizontal and vertical directions to the 
plain surface of the $\mathrm{C} / \mathrm{G}$ composite samples [17]. The thermal conductivity in the horizontal direction decreased gradually from $10 \mathrm{wt} \%$ to $80 \mathrm{wt} \%$ of carbonized wood. The thermal conductivity in the vertical direction decreased sharply with the increase in the weight fraction of carbonized wood from $0 \mathrm{wt} \%$ to 10 $\mathrm{wt} \%$, followed by a slight decrease in thermal conductivity to $80 \mathrm{wt} \%$. As a consequence, the anisotropic thermal conductivity of $\mathrm{C} / \mathrm{G}$ composites was improved, as shown in Fig. 4(b), compared with SL graphite and carbonized wood or natural graphite in a previous study [5]. This behavior has been suggested to be influenced by a layered structure of $\mathrm{C} / \mathrm{G}$ composites, as shown in Fig. 3. Alternate layers of graphite and carbonized wood result in good thermal conductivity in the horizontal direction within the graphite layer due to the high-order microstructure, and a poor thermal conductivity in the vertical direction due to the presence of a layer consisting of disordered microstructure between the graphite layers. Skorokhod showed that markedly different thermal conductivities of the layers resulted in the anisotropic thermal conductivity of the layered composite [21]. Therefore, even thin layers of graphite covered a thick layer of carbonized wood, as shown in Fig. 1f, and the improved anisotropic thermal conductivity of the $\mathrm{C} / \mathrm{G}=80 / 20$ sample was better than that of the SL graphite and SL carbonized wood.

The thermal conductivity of $\mathrm{C} / \mathrm{G}$ composites using particles of sizes $32-45$ and $63-90 \mu \mathrm{m}$ abruptly decreased in the horizontal direction with the increase in weight fraction of carbonized wood, resulting in a sharp decrease in the $\mathrm{H} / \mathrm{V}$ ratio, as shown in Figs. 4-b. These results can be explained by considering graphite and carbonized wood layers. The decrease in the thermal conductivity of the $\mathrm{C} / \mathrm{G}$ composites was determined primarily by the decrease in thermal conductivity of the graphite layer related to the increase in particle size, as found on the SL graphite, due to the effect of agglomerated graphite particles (see Sect. 3.2.1). However, the H/V ratio of the graphite layer seems not to be affected by the particle size. Therefore, the decreasing $\mathrm{H} / \mathrm{V}$ ratio of $\mathrm{C} / \mathrm{G}$ composites related to the increase in particle size is suggested to be determined by the heat flow behavior in the carbonized wood layer. As found on the SL carbonized wood (see Sect. 3.2.1), due to the orientation of particles of sizes 32-45 and 63-90 $\mu \mathrm{m}$, the heat flows in the horizontal direction are 2.31 and 1.66 times faster, respectively, than those in the vertical direction. This shows that with the increase in particle size, the carbonized wood layer has less anisotropic thermal conductivity. The heat flow in the vertical direction increases more significantly than in the horizontal direction. As a consequence, the use of the larger particle size in the $\mathrm{C} / \mathrm{G}$ composites resulted in the reduction of the $\mathrm{H} / \mathrm{V}$ ratio of thermal conductivity. 
To find the optimum conditions for the $\mathrm{H} / \mathrm{V}$ ratio, experimental measurement and calculation were performed. Figures $4 \mathrm{a}-\mathrm{b}$ shows the results of both methods. The highest $\mathrm{H} / \mathrm{V}$ ratio in the experimental data was obtained at $10 \mathrm{wt} \%$ of carbonized wood, because the $\mathrm{C} / \mathrm{G}=10 / 90$ sample had the thickest layer of graphite and the thinnest layer of carbonized wood compared with the other samples. The thickness of the graphite layer on the $\mathrm{C} / \mathrm{G}=10 / 90$ sample showed faster heat flow within the graphite layer than the other samples. On the other hand, the carbonized wood layer in the $\mathrm{C} / \mathrm{G}=10 / 90$ sample was able to effectively reduce the heat flow in the vertical direction, which was not markedly differed from the other samples. This shows that the thickness ratio of the graphite and carbonized wood layers determined the thermal conductivity in the horizontal and vertical directions of $\mathrm{C} / \mathrm{G}$ composites [22], resulting in optimum $\mathrm{H} / \mathrm{V}$ ratios of $10.17,8.90$, and 8.60 using particle sizes of $25-32,32-45$, and $63-90 \mu \mathrm{m}$, respectively. The calculated $\mathrm{H} / \mathrm{V}$ ratio of the $\mathrm{C} / \mathrm{G}$ composites was performed by curve fittings. The curves shown in Fig. $4 \mathrm{a}$ and Table 3 were obtained by testing different equations and using the best fit of the experimental values of the thermal conductivity in the horizontal and vertical directions. Figure 4(b) shows the results of the $\mathrm{H} / \mathrm{V}$ ratio calculated from curve fitting. Differential calculations were performed to obtain the highest point of the $\mathrm{H} / \mathrm{V}$ ratios from the curve fitting at position $y=f^{\prime}(x)=0$. The highest $\mathrm{H} / \mathrm{V}$ ratios of $\mathrm{C} / \mathrm{G}$ composites using particles of sizes $25-32,32-45$, and $63-90 \mu \mathrm{m}$ were $9.22,10.4$, and 9.78, respectively, which were obtained at $16.4,19.0$, and $17.5 \mathrm{wt} \%$ of carbonized wood, respectively. There is good agreement between the highest $\mathrm{H} / \mathrm{V}$ ratio obtained by curve-fitting and experimental measurements. Therefore, the curve-fitting method can be used to estimate the optimum $\mathrm{H} / \mathrm{V}$ ratio of a few samples of layered composites.

\subsubsection{Effect of interlayer interfaces}

Comparison between the thermal conductivity values of $\mathrm{C} / \mathrm{G}$ composites obtained by calculation and experimental measurement, as presented in Table 3, were used to estimate the effect of the interlayer interface. The values of the calculated thermal conductivity of the $\mathrm{C} / \mathrm{G}$ composites used experimentally measured data for SL graphite (G100) and SL carbonized wood (C100). These calculations for the horizontal and vertical directions were performed using the following equations [19, 22]:

$k_{H}=d_{G} / d_{\text {total }} k_{H-G}+d_{C} / d_{\text {total }} k_{H-C}$ 
$k_{V}=\frac{1}{d_{G} / d_{\text {total }}\left(1 / k_{V-G}\right)+d_{C} / d_{\text {total }}\left(1 / k_{V-C}\right)}$

where $k_{H}$ and $k_{V}$ are the effective thermal conductivities in the horizontal and vertical directions of the $\mathrm{C} / \mathrm{G}$ composites, $d_{\text {total }}$ is the total thickness of the $\mathrm{C} / \mathrm{G}$ composites, $d_{G}$ and $d_{C}$ are thicknesses of the graphite (total of $d_{G I}$ and $d_{G 2}$ ) and carbonized wood layers presented in Table 2, $k_{H-G}$ and $k_{H-C}$ are the thermal conductivities of the graphite and carbonized wood layers in the horizontal direction, and $k_{V-G}$ and $k_{V-C}$ are thermal conductivities of the graphite and carbonized wood layers in the vertical direction. Both calculations assume an infinite heat transfer coefficient for interlayer interface, which gives no temperature decrease across the interface. The values of the calculated thermal conductivity in the horizontal and vertical directions were significantly higher than those of the experimental measurements for all three particle sizes, except for the particle size of 25-32 $\mu \mathrm{m}$ in the vertical direction. This indicated that the differences between the values of the calculated and measured thermal conductivities are affected by the heat reduction on the interlayer interface. The reduction in the value of the experimental measured thermal conductivity is caused by the interface thermal resistance [23].

An assessment of the effect of the interlayer interfaces on the thermal conductivity of the $\mathrm{C} / \mathrm{G}$ composites is illustrated in Fig. 5a. The values of the experimental measured thermal conductivity of the $\mathrm{C} / \mathrm{G}=10 / 90$ sample prepared with two to nine layers are presented. The thermal conductivities in the horizontal and vertical directions decrease sharply with the increase in the number of layer from two to five, the thermal conductivity was then changed slightly with the increase in the number of layers from five to nine. The presence of interlayer interfaces influences the reduction in the thermal conductivity due to the presence of thermal resistance at the interfaces $[19,23]$. SEM observation confirmed that the graphite and carbonized wood layers were separated by a rough interface, as shown in Fig. 2f. Thermal resistance can be suggested to exist at a rough interlayer interface [24]. When heat transfer occurs at the interface, heat reduction, which depends on the degree of imperfection, occurs. With the increase in the number of layers to five layers, the thermal resistance increased, and the thermal conductivity decreased. Figure 5a shows that when the number of layers exceeds five, the contribution of interlayer interfaces in reducing the thermal conductivity becomes insignificant due to the discontinuity or the imperfect layer of carbonized wood, as shown in Figs. 6c-d.

Figure $5 \mathrm{~b}$ shows that the $\mathrm{H} / \mathrm{V}$ ratio of $\mathrm{C} / \mathrm{G}$ composites tended to decrease with the increase in 
the number of layers. This can be explained by the contribution of the interlayer interface on reducing the thermal conductivity, especially in the horizontal direction, as compared with that in the vertical direction.

\subsubsection{Thermal conductivity at temperatures ranging from $25^{\circ} \mathrm{C}$ to $150{ }^{\circ} \mathrm{C}$}

Figure 7 shows the temperature dependence of the thermal conductivity in the vertical direction of SL graphite (G100), SL carbonized wood (C100), and $\mathrm{C} / \mathrm{G}=10 / 90$. The thermal conductivity of SL graphite under the vacuum condition decreased in temperature ranging from $25^{\circ} \mathrm{C}$ to $150^{\circ} \mathrm{C}$, whereas this trend was not observed in air. The decreasing thermal conductivity of graphite is due to increased scattering of the phonons with temperature $[8,25]$. In the case of SL carbonized wood and $C / G=10 / 90$, the thermal conductivity increased with temperature, which agrees with previous studies on carbonized wood and polyetherimide-carbon nanofiber composites [26, 27], because the specific heat capacity increases with the increase in temperature. The difference in the temperature trend between graphite and carbonized wood corresponds to the crystallite size $\left(L_{a}\right)$. As the crystallite size decreases, the peak thermal conductivity shifts to a higher temperature [20]. Figure 7 shows that, for the three-layer $\mathrm{C} / \mathrm{G}$ composites $(\mathrm{C} / \mathrm{G}=10 / 90$ sample), the carbonized wood layer increased the thermal conductivity of the composites.

Thermal conductivities in air were larger than those under vacuum conditions, as shown for the $\mathrm{C} / \mathrm{G}=10 / 90$ sample using particles of size $63-90 \mu \mathrm{m}$. Particles of size $63-90 \mu \mathrm{m}$ oriented in the vertical direction retain their cellular structure of wood. Under vacuum conditions, the lumens become insulations because the heat transfer by air disappeared. Consequently, the thermal conductivity diminishes. In contrast, there were no differences between the values of thermal conductivity measured in air and those measured in a vacuum on $\mathrm{C} / \mathrm{G}$ composites prepared using particles of size $25-32 \mu \mathrm{m}$. Therefore, the $\mathrm{H} / \mathrm{V}$ ratio of $\mathrm{C} / \mathrm{G}$ composites using particles of size $25-32 \mu \mathrm{m}$ in a vacuum can be predicted to be similar to that in air.

\subsection{Raman Spectroscopy}

Figures $8 \mathrm{a}-\mathrm{b}$ shows Raman spectra in the $1,100-1,800 \mathrm{~cm}^{-1}$ region of graphite and carbonized wood before and after heat treatment. All of the curves exhibited two Raman bands, which are described as $\mathrm{G}$ and $\mathrm{D}$ bands. The $\mathrm{G}$ band corresponds to the $\mathrm{E}_{2 \mathrm{~g}}$ vibrational modes, and the $\mathrm{D}$ band is assigned to a breathing mode of $\mathrm{A}_{1 \mathrm{~g}}$ [28]. The $\mathrm{D}$ band accounts for the presence of a defect or structural disorder, and the $\mathrm{G}$ band for the graphitic order. Graphite showed narrow Raman G and D bands, whereas broader Raman bands were found for carbonized wood. This shows that graphite and carbonized wood had 
different microstructures as highly ordered and disordered/turbostratic, respectively. The spectra of graphite and carbonized wood were consistent with the spectra of commercial graphite and black graphite [29-30] as well as a previous spectrum of carbonized wood [9], respectively.

Raman spectroscopy studies have shown that heat treatment affected the structure of carbonized wood, as shown in Fig. 8a. After heat treatment, the full width at half maximum (FWHM) of G bands and intensity ratios of $I_{d} / I_{g}$ increased slightly from $56 \mathrm{~cm}^{-1}$ to $62-63 \mathrm{~cm}^{-1}$, and from 0.50 to 0.56-0.57, respectively. The FWHM of D bands decreased from $119 \mathrm{~cm}^{-1}$ to $113-116 \mathrm{~cm}^{-1}$, except on samples of particle sizes of 25-32. These values can be interpreted as indicative of the carbonized wood becoming slightly more structurally disordered due to the heat treatment. In the case of graphite, the heat treatment in the present study had no structural effects. Figure $8 \mathrm{~b}$ shows the positions of the Raman $\mathrm{G}$ and D bands, the FWHM of the G bands and the intensity ratios of $I_{d} / I_{g}$ of graphite were similar before and after heat treatment, as observed at approximately $1,580 \mathrm{~cm}^{-1}, 1,354 \mathrm{~cm}^{-1}, 21 \mathrm{~cm}^{-1}$, and 0.22 , respectively, which is consistent with the results of a previous study [29].

An empirical formula developed by Tuinstra and Koening [28] was used to determine the crystallite size or coherence length $\left(L_{a}\right)$ from Raman peak data for graphite and carbonized wood:

$L_{a}=\frac{(43.5 \AA)}{I_{d} / I_{g}}$

The heat treatment caused the $L_{a}$ of carbonized wood to decrease from $87 \AA$ to approximately $76 \AA$ with increasing $I_{d} / I_{g}$. For disordered carbon material, the ratio $I_{d} / I_{g}$ is often reported to be inversely proportional to the $L_{a}$ of the graphene units [29]. In the case of graphite, $L_{a}$ was found to be constant at approximately $200 \AA$ before and after the heat treatment, which is similar to the value reported in a previous study [30].

\section{Conclusions}

Alternate layers of graphite and carbonized wood improved the anisotropic thermal conductivity of $\mathrm{C} / \mathrm{G}$ composites. The weight fraction of carbonized wood related to layer thicknesses affected the thermal conductivity and the $\mathrm{H} / \mathrm{V}$ ratio. The highest $\mathrm{H} / \mathrm{V}$ ratio of 10.17 was obtained at 10 wt $\%$ of carbonized wood particles with a size of $25-32 \mu \mathrm{m}$, which showed good agreement with the ratio determined by curve fitting. The influence of particle size on the thermal conductivity and the $\mathrm{H} / \mathrm{V}$ ratio was found to be determined by the use of agglomerated particles of graphite and the morphology of 
carbonized wood layer. The interlayer interface of graphite and carbonized wood affected the reduction of thermal conductivity and the $\mathrm{H} / \mathrm{V}$ ratio. The thermal conductivity of $\mathrm{C} / \mathrm{G}$ composites increased in the temperature range of from $25{ }^{\circ} \mathrm{C}$ to $150{ }^{\circ} \mathrm{C}$. The values of thermal conductivity of $\mathrm{C} / \mathrm{G}$ composites using particle sizes of 25-32 $\mu$ m measured in air were not significantly different than those measured under vacuum conditions. In the case of a particle size of $63-90 \mu \mathrm{m}$, the thermal conductivity measured in air was higher than that measured under vacuum conditions. Heat treatment caused carbonized wood to become more structurally disordered, but in the case of graphite had no structural effects.

The alternate layered composites of two-phase components, such as graphite and carbonized wood, may lead to thermal management applications, for example, in an SPS. Improved thermal conductivity is necessary in order to obtain an effective thermal conductive material.

\section{Acknowledgment}

This research was carried out with support from a Grant-in-Aid for Scientific Research (17656309) from the Ministry of Education, Science, and Culture of Japan.

\section{References}

[1] Qiu H, Song Y, Liu L, Zhai G, Shi J (2003) Carbon 41: 973

[2] Fitzer E (1983) Carbon 25:163

[3] Chung DDL (2002) J Mater Sci 37:1475. doi:10.1023/A:1014915307738

[4] Nagano H, Ohnishi A, Nagasaka Y, Mori YH, Nagashima A (2006) Int J Thermophys 27:114

[5] Slack GA (1962) Phys Rev 127:694

[6]. Null MR, Lozier WW, Moore AW (1973) Carbon 11:81

[7] Desai S, Rand B (2007) In: Proceeding international conference on carbon 2007, Seattle

[8] Lutcov AI, Volga VI, Dymov BK (1970) Carbon 8:753

[9] Ishimaru K, Hata T, Bronsveld P, Imamura Y (2007) J Mater Sci 42:2662. doi:10.1007/s10853-006-1361-4

[10] Ishihara S (1996) In: Salamone JC (ed.) Polymeric material encyclopedia 2, CRC Press, Boca Raton

[11] Kumar M, Gupta RC (1993) J Mater Sci 28:440 
[12] Parker WJ, Jenkins RJ, Butler CP, Abbott GL (1961) J Appl Phys 32:1679

[13] Krupa I, Chodak I (2001) Eur Polym J 37:2159

[14] Hongsheng Z, Tongxiang L, Jie Z, Ziqiang L, Chunhe T (2006) Rare Met 25: 347

[15] Hoshi S, Kojima A, Goto M (2000) Carbon 38:1879

[16] Subyakto, Hata T, Kawai S, Imamura Y, Ide I (2000) J Wood Sci 46:16

[17] Bigg DM (1986) Polym Compos 7:125

[18] Ragland KW, Aerts DJ, Baker AJ (1991) Bioresour Techno 37:161

[19] Ravichandran KS, An K, Dutton RE, Semiatin SL (1999) J Am Ceram Soc 82:673

[20] Taylor R (2000) In: Kelly A, Zweben C (eds in chief), Warren R (ed) Comprehensive composite materials, vol 4. Elsevier

[21] Skorokhod VV (2003) Powder Metall and Metal Ceram 42:437.

[22] Ervin VJ, Klett JW, Mundt CM (1999) J Mater Sci 34:3545. doi:10.1023/A:1004674308487

[23] Radhakrishna MC, Doerr HJ, Deshpandey CV, Bunshah RF (1989) Surf Coat Techno

[24] Absi J, Smith DS, Grandjean S, Berjonnaux J (2005) J Eur Ceram Soc 25:367

[25] Manocha LM, Warrier A, Manocha S, Sathiyamoorthy D, Banerjee S (2006) Carbon 44:488

[26] Gupta M, Yang J, Roy C (2003) Fuel 82:919

[27] Kumar S, Rath T, Mahaling RN, Reddy CS, Das CK, Pandey KN, Srivastava RB, Yadaw SB (2007) Mater Sci Eng B 141:61

[28]. Tuinstra F, Koenig JL (1970) J Chem Phys 53:1126

[29] Anggoni K (1993) Carbon 31:537

[30] Nikiel L, Jagodzinski PW (1993) Carbon 31:1313 
Table 1. Density and layer thicknesses of three-layer $\mathrm{C} / \mathrm{G}$ composites

\begin{tabular}{|c|c|c|c|c|c|c|c|}
\hline \multirow{2}{*}{$\begin{array}{c}\text { Particle } \\
\text { Size }(\mu \mathrm{m})\end{array}$} & & \multicolumn{6}{|c|}{ Weight fraction of carbonized wood (wt\%) } \\
\hline & & 10 & 20 & 33 & 60 & 70 & 80 \\
\hline \multirow{5}{*}{$25-32$} & $d_{G l}(\mathrm{~mm})$ & 0.30 & 0.28 & 0.24 & 0.14 & 0.06 & 0.05 \\
\hline & $d_{C}(\mathrm{~mm})$ & 0.17 & 0.35 & 0.54 & 0.81 & 0.99 & 1.10 \\
\hline & $d_{G 2}(\mathrm{~mm})$ & 0.32 & 0.19 & 0.13 & 0.11 & 0.07 & 0.05 \\
\hline & $d_{\text {total }}(\mathrm{mm})$ & 0.79 & 0.82 & 0.90 & 1.06 & 1.12 & 1.20 \\
\hline & $\rho\left(\mathrm{g} / \mathrm{cm}^{3}\right)$ & 1.55 & 1.44 & 1.38 & 1.17 & 1.13 & 1.10 \\
\hline \multirow{5}{*}{$32-45$} & $d_{G I}(\mathrm{~mm})$ & 0.33 & - & 0.18 & 0.13 & - & - \\
\hline & $d_{C}(\mathrm{~mm})$ & 0.14 & - & 0.48 & 0.78 & - & - \\
\hline & $d_{G 2}(\mathrm{~mm})$ & 0.29 & - & 0.20 & 0.13 & - & - \\
\hline & $d_{\text {total }}(\mathrm{mm})$ & 0.76 & - & 0.86 & 1.04 & - & - \\
\hline & $\rho\left(\mathrm{g} / \mathrm{cm}^{3}\right)$ & 1.61 & - & 1.45 & 1.22 & - & - \\
\hline \multirow{5}{*}{$63-90$} & $d_{G l}(\mathrm{~mm})$ & 0.31 & - & 0.21 & 0.15 & - & - \\
\hline & $d_{C}(\mathrm{~mm})$ & 0.12 & - & 0.45 & 0.76 & - & - \\
\hline & $d_{G 2}(\mathrm{~mm})$ & 0.33 & - & 0.22 & 0.14 & - & - \\
\hline & $d_{\text {total }}(\mathrm{mm})$ & 0.77 & - & 0.88 & 1.05 & - & - \\
\hline & $\rho\left(\mathrm{g} / \mathrm{cm}^{3}\right)$ & 1.59 & - & 1.42 & 1.24 & - & - \\
\hline
\end{tabular}

The layer thicknesses are the average values from the measurement at 5 points on each sample

$d_{G 1}$ and $d_{G 2}$, layer thickness of surface and rear surface of graphite; $d_{C}$, that of carbonized wood; $d_{\text {total }}$, total thickness of $\mathrm{C} / \mathrm{G}$ composites; $\rho$, oven dried density 
Table 2. Thermal conductivity of $\mathrm{C} / \mathrm{G}$ composites, single layer composite of graphite and carbonized wood

\begin{tabular}{|c|c|c|c|c|c|c|c|c|}
\hline \multirow{2}{*}{$\begin{array}{c}\text { Particle } \\
\text { Size }(\mu \mathrm{m})\end{array}$} & \multirow{2}{*}{ Specimen } & \multirow{2}{*}{$\begin{array}{l}\text { Sample } \\
\text { name }\end{array}$} & \multirow{2}{*}{$\begin{array}{l}\text { Structure } \\
\text { (Layers) }\end{array}$} & \multicolumn{3}{|c|}{ Measured } & \multicolumn{2}{|c|}{ Calculated } \\
\hline & & & & $k_{H}$ & $k_{V}$ & $\begin{array}{l}H / V \\
\text { ratio }\end{array}$ & $k_{H}$ & $k_{V}$ \\
\hline \multirow[t]{9}{*}{$25-32$} & SL-G & G100 & 1 & 33.30 & 8.81 & 3.78 & - & - \\
\hline & $\mathrm{C} / \mathrm{G}$ composite & $\mathrm{C} / \mathrm{G}=5 / 95$ & 3 & 18.93 & 3.45 & 5.49 & - & - \\
\hline & & $\mathrm{C} / \mathrm{G}=10 / 90$ & 3 & 19.85 & 1.95 & 10.17 & 26.37 & 1.92 \\
\hline & & $\mathrm{C} / \mathrm{G}=20 / 80$ & 3 & 13.25 & 1.58 & 8.40 & 19.58 & 1.09 \\
\hline & & $\mathrm{C} / \mathrm{G}=33 / 67$ & 3 & 8.86 & 1.20 & 7.41 & 14.38 & 0.80 \\
\hline & & $\mathrm{C} / \mathrm{G}=60 / 40$ & 3 & 5.66 & 0.81 & 7.02 & 8.74 & 0.64 \\
\hline & & $\mathrm{C} / \mathrm{G}=70 / 30$ & 3 & 5.23 & 0.80 & 6.55 & 4.78 & 0.56 \\
\hline & & $\mathrm{C} / \mathrm{G}=80 / 20$ & 3 & 3.53 & 0.61 & 5.80 & 3.86 & 0.54 \\
\hline & SL-C & $\mathrm{C} 100$ & 1 & 1.14 & 0.50 & 2.31 & - & - \\
\hline \multirow[t]{5}{*}{$32-45$} & SL G & G100 & 1 & 29.25 & 6.56 & 4.46 & - & - \\
\hline & $\mathrm{C} / \mathrm{G}$ composite & $\mathrm{C} / \mathrm{G}=10 / 90$ & 3 & 17.79 & 2.00 & 8.90 & 24.13 & 2.97 \\
\hline & & $\mathrm{C} / \mathrm{G}=33 / 67$ & 3 & 6.60 & 0.93 & 6.26 & 13.72 & 1.41 \\
\hline & & $\mathrm{C} / \mathrm{G}=60 / 40$ & 3 & 5.67 & 0.85 & 6.68 & 8.38 & 1.11 \\
\hline & SL-C & $\mathrm{C} 100$ & 1 & 1.43 & 0.87 & 1.65 & - & - \\
\hline \multirow[t]{5}{*}{ 63-90 } & SL-G & G100 & 1 & 25.63 & 7.06 & 3.63 & - & - \\
\hline & $\mathrm{C} / \mathrm{G}$ composite & $\mathrm{C} / \mathrm{G}=10 / 90$ & 3 & 15.78 & 1.83 & 8.60 & 21.52 & 3.30 \\
\hline & & $\mathrm{C} / \mathrm{G}=33 / 67$ & 3 & 6.11 & 0.95 & 4.08 & 13.24 & 1.48 \\
\hline & & $\mathrm{C} / \mathrm{G}=60 / 40$ & 3 & 6.86 & 1.12 & 6.14 & 8.09 & 1.11 \\
\hline & SL-C & $\mathrm{C} 100$ & 1 & 1.40 & 0.84 & 1.66 & - & - \\
\hline
\end{tabular}

The meaning of sample names refers to Fig. 1

All samples were prepared by heating at $700^{\circ} \mathrm{C}$, under pressure of $50 \mathrm{MPa}$ and vacuum conditions

Thermal conductivity is calculated by using Eq. (3). Calculated $k_{H}$ and $k_{V}$ are determined by using Eqs. (4) and (5)

$k_{H}$, thermal conductivity in the horizontal direction; $k_{V}$, that of in the vertical direction; $H / V$ ratio, ratio of thermal conductivity between in the horizontal and in the vertical directions; SL-G, single layer composite, of graphite; SL-C, that of carbonized wood 
Table 3. Results of curve-fitting analysis

\begin{tabular}{cclc}
\hline Particle size $(\mu \mathrm{m})$ & Direction & \multicolumn{1}{c}{ Equations } \\
\hline $25-32$ & Horizontal & $y_{H}=-227.2+(33.3+227.2) /\left(1+(x / 39080)^{0.330}\right)$ & $(6)$ \\
& Vertical & $y_{V}=1.96 e^{(-x / 78.9)}+6.92 e^{(-x / 3.46)}-0.066$ \\
$32-45$ & Horizontal & $y_{H}=21.3 e^{(-x / 12.9)}+8.14+(-0.064) x$ \\
& Vertical & $y_{V}=5.69 e^{(-x / 6.18)}+0.873$ \\
\multirow{3}{*}{$63-90$} & Horizontal & $y_{H}=16.5 e^{(-x / 1.0)}+9.30+(-0.073) x$ \\
& Vertical & $y_{V}=0.967+6.09 e^{(-0.196 x)}$ \\
& &
\end{tabular}



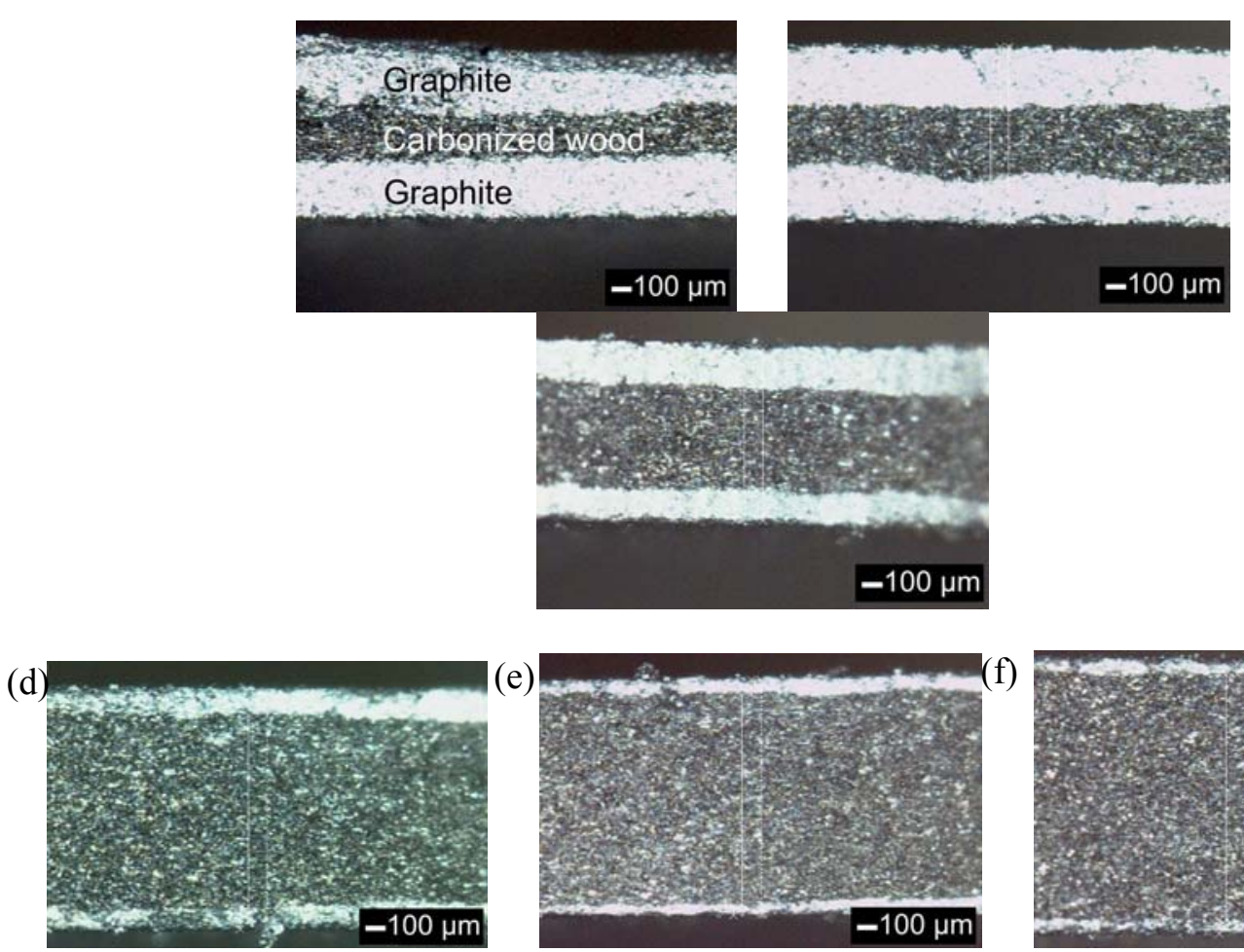

(e)
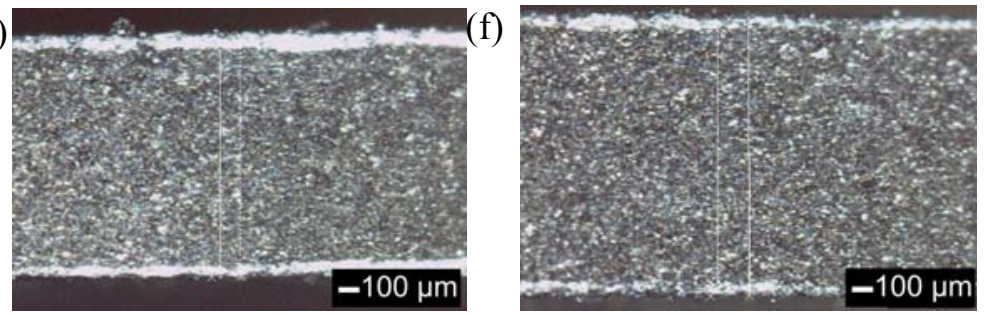

Fig. 1. Cross-section images of three-layer $\mathrm{C} / \mathrm{G}$ composites using particle with the size of 25-32 $\mu \mathrm{m}$ in relation to weight fraction of carbonized wood: $\mathrm{C} / \mathrm{G}=10 / 90$ (a); $\mathrm{C} / \mathrm{G}=20 / 80$ (b); $\mathrm{C} / \mathrm{G}=33 / 67$ (c); $\mathrm{C} / \mathrm{G}=40 / 60$ (d); $\mathrm{C} / \mathrm{G}=70 / 30$ (e); and $\mathrm{C} / \mathrm{G}=80 / 20$ (f). Sample name shows weight fractions of carbonized wood and graphite used. For example, $\mathrm{C} / \mathrm{G}=10 / 90$ means the sample contains $10 \mathrm{wt} \%$ of carbonized wood and $90 \mathrm{wt} \%$ of graphite 

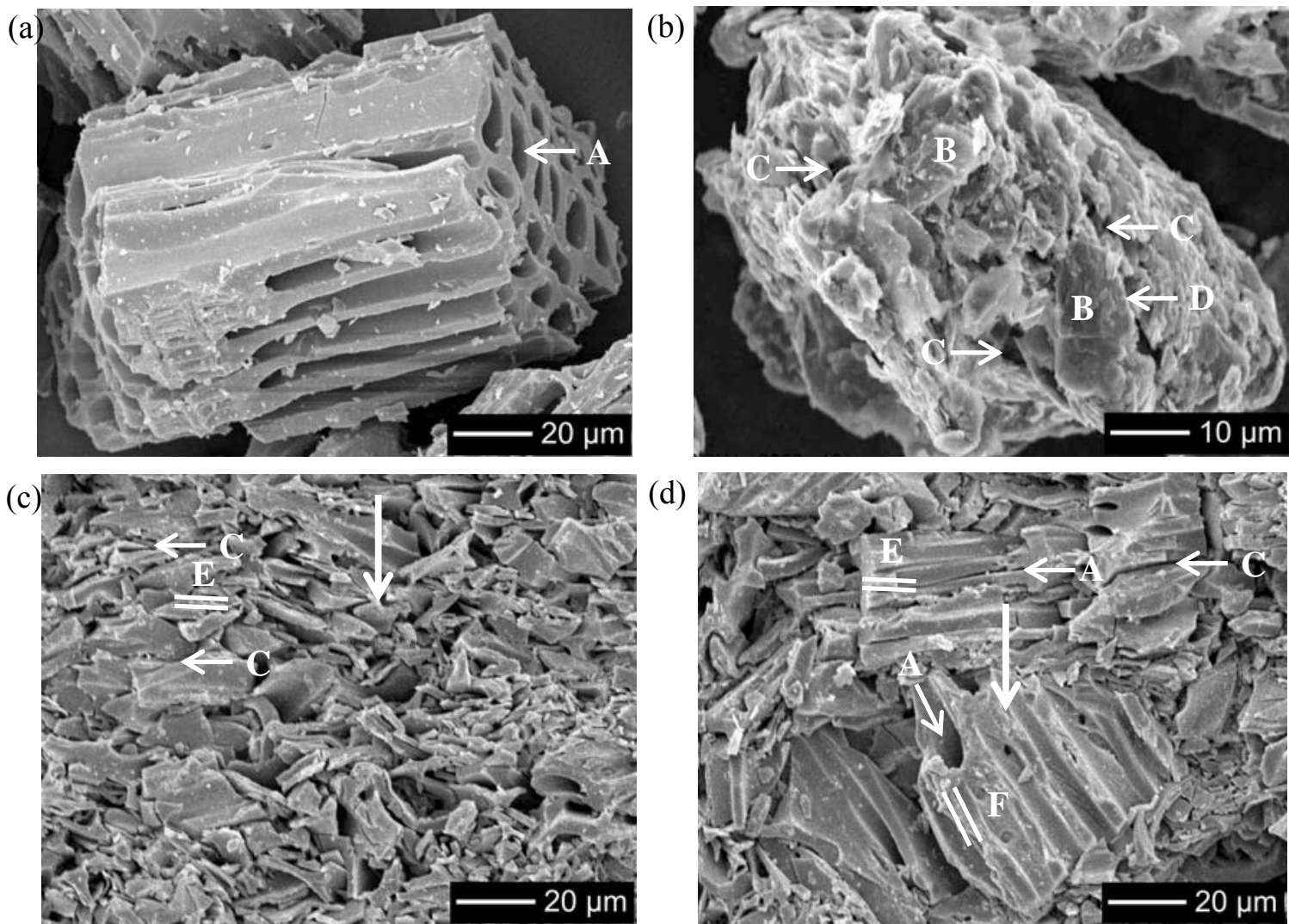

(d)

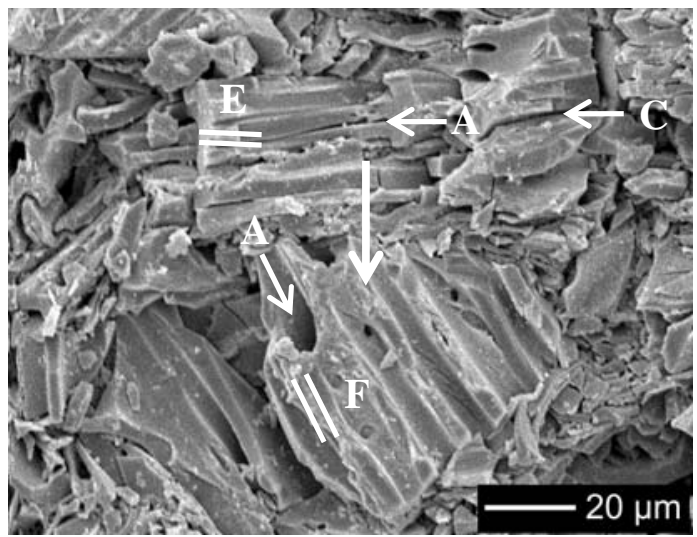

(e)
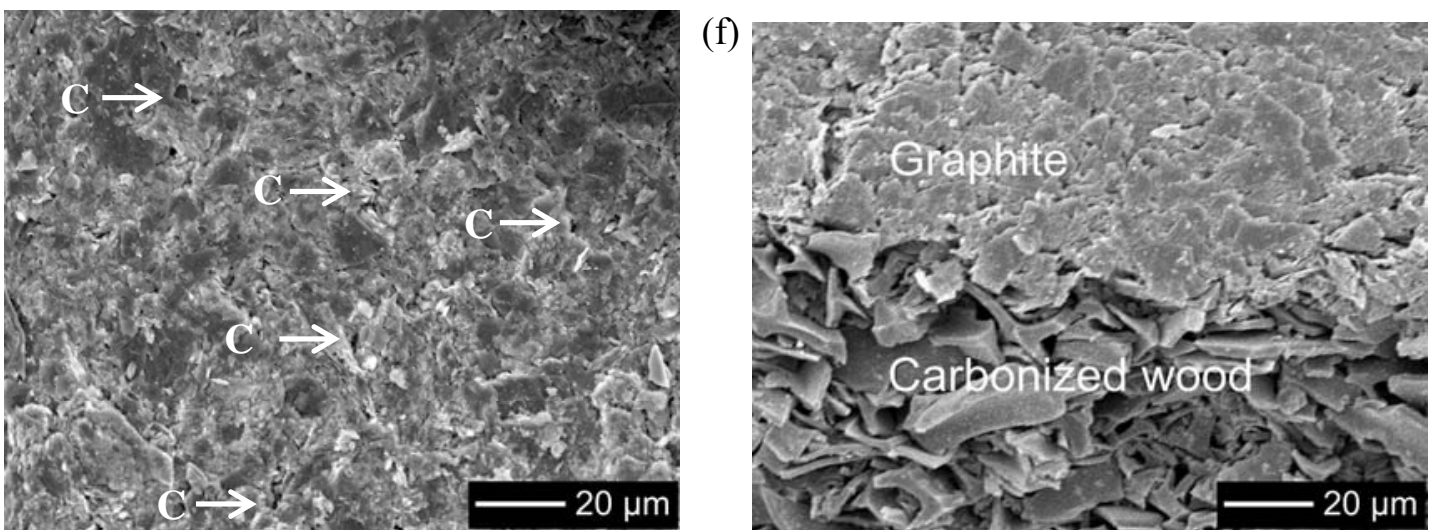

Fig. 2. SEM images of a single particle of carbonized wood with the size of $63-90 \mu \mathrm{m}$ that exhibits lumens $(A)$; $\mathbf{b}$ single agglomerated particle of graphite with the size of $63-90 \mu \mathrm{m}$ that consists fine particles $(B)$, voids $(C)$ and particle interface $(D)$; c cross section of carbonized wood layer in $\mathrm{C} / \mathrm{G}$ composites using particle size of $25-32 \mu \mathrm{m}$ with voids $(C)$ occurred that was oriented perpendicular $(E)$ to pressure direction (vertical arrow) and $\mathbf{d}$ that of using particle size of $63-90 \mu \mathrm{m}$ that show broken particles $(E)$ and not much broken particles $(F)$ oriented perpendicular and in an angle around $45^{\circ}$ to the pressure direction (vertical arrow), respectively; e surface area of graphite layer that exhibits voids $(C)$; $\mathbf{f}$ interlayer interface area of between graphite and carbonized wood 


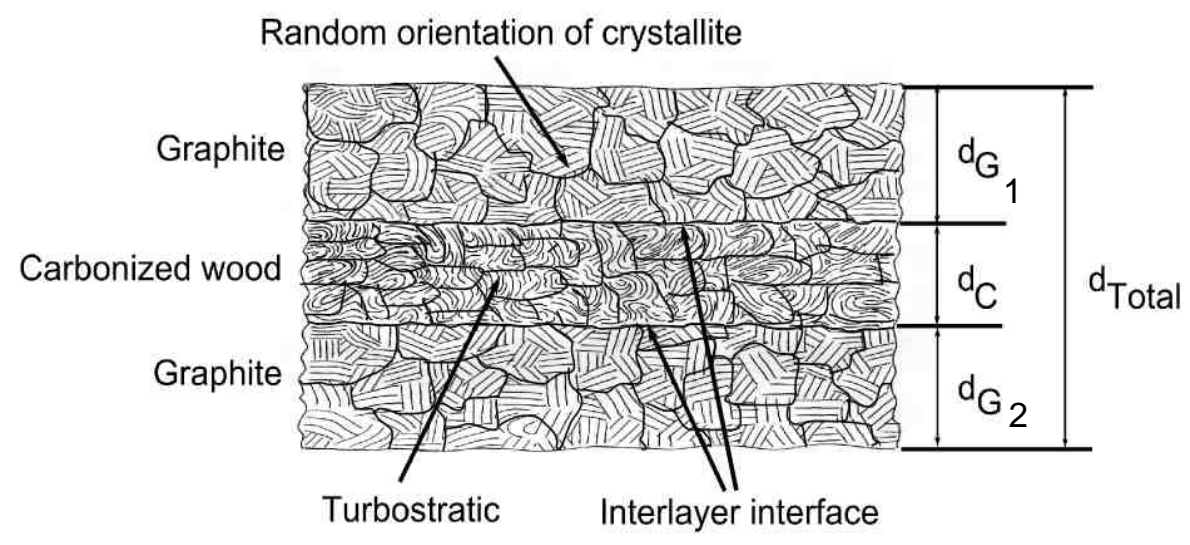

Fig. 3. Schematic structure of three-layer laminated $\mathrm{C} / \mathrm{G}$ composites 
(a)
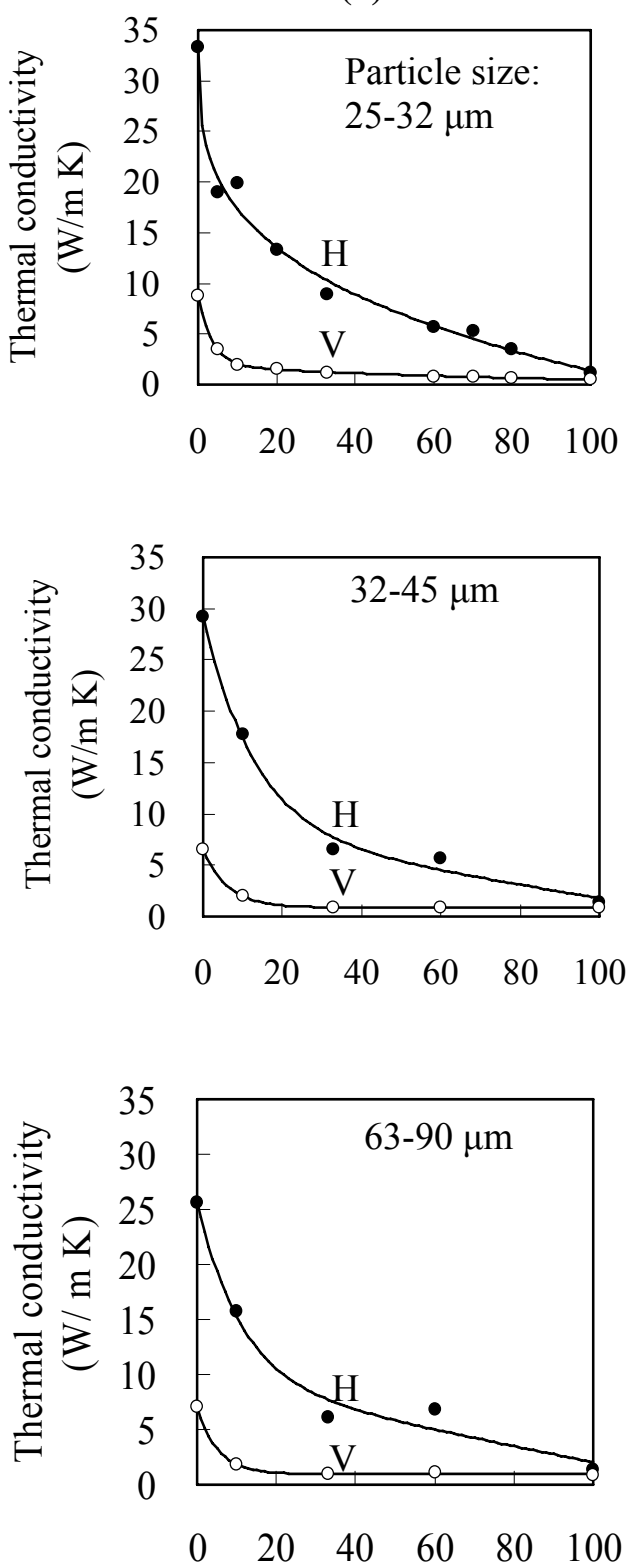

Weight fraction of carbonized wood (wt.\%) (b)
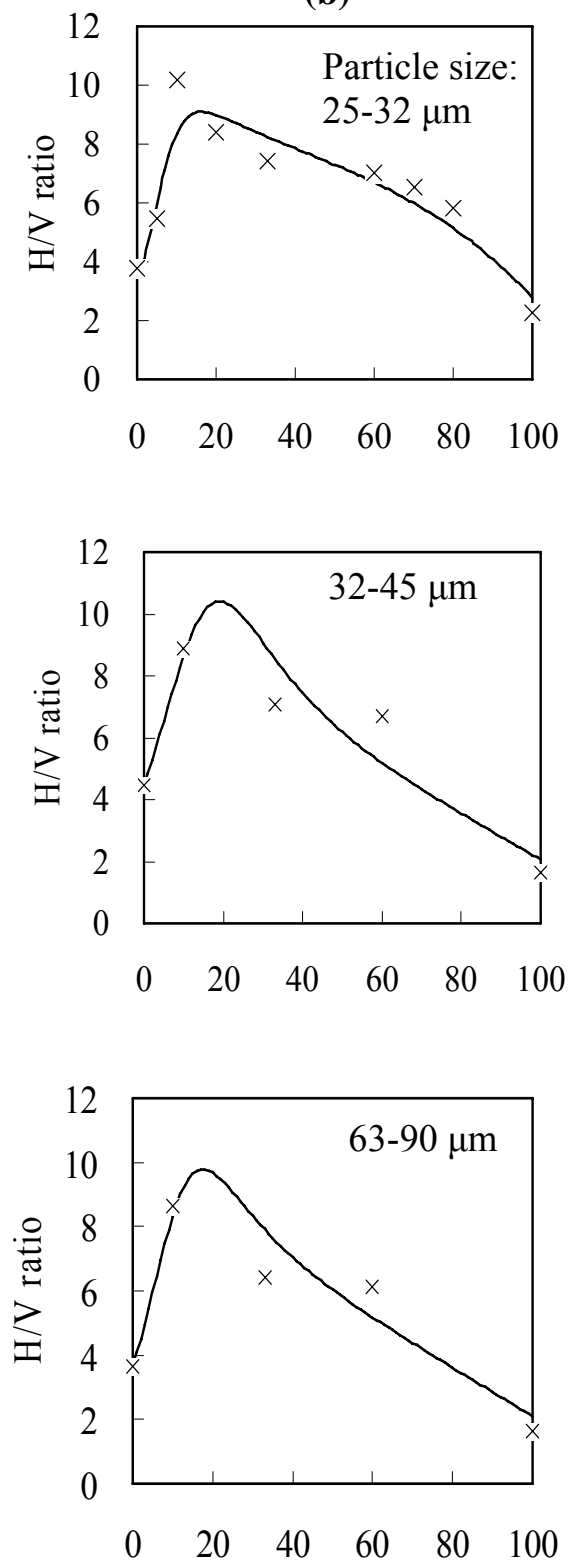

Weight fraction of carbonized wood (wt.\%)

Fig. 4. Thermal conductivity (a) and $\mathrm{H} / \mathrm{V}$ ratio (b) of $\mathrm{C} / \mathrm{G}$ composites using particle sizes of $25-32,32-45$ and $63-90 \mu \mathrm{m}$ shown in relation to weight fraction of carbonized wood. Filled circles, experimental measured thermal conductivity in the horizontal direction $(\mathrm{H})$; open circles, that of in the vertical direction $(\mathrm{V})$; diagonal crosses, $\mathrm{H} / \mathrm{V}$ ratio of experimental data, solid lines, curves-fitting 
(a)

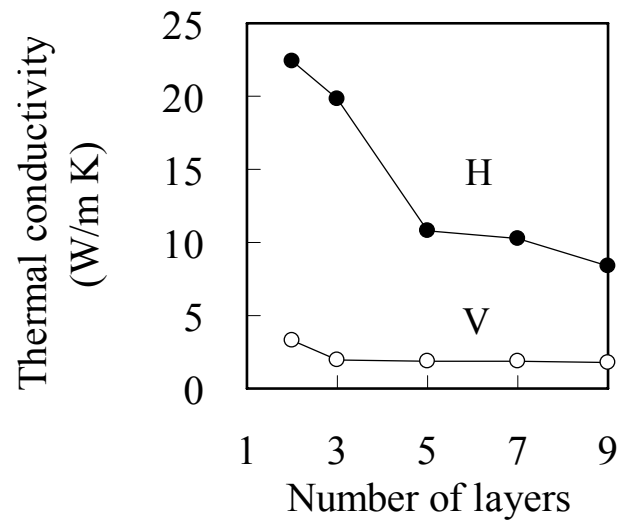

(b)

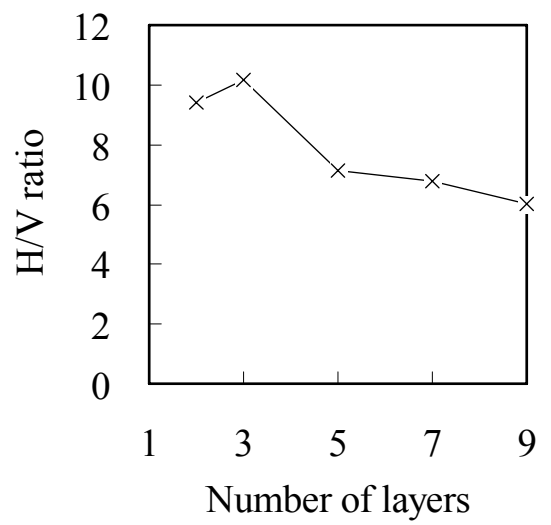

Fig. 5. Relation between number of layers with (a) thermal conductivity and (b) H/V ratio of samples $\mathrm{C} / \mathrm{G}=10 / 90$ using particle size of $25-32 \mu \mathrm{m}$. Filled circles, thermal conductivity in the horizontal direction $(\mathrm{H})$; open circles, that of in the vertical direction $(\mathrm{V})$; diagonal crosses, $\mathrm{H} / \mathrm{V}$ ratio. The meaning of sample name of $\mathrm{C} / \mathrm{G}=10 / 90$ is given in Fig. 1 caption 
(a)

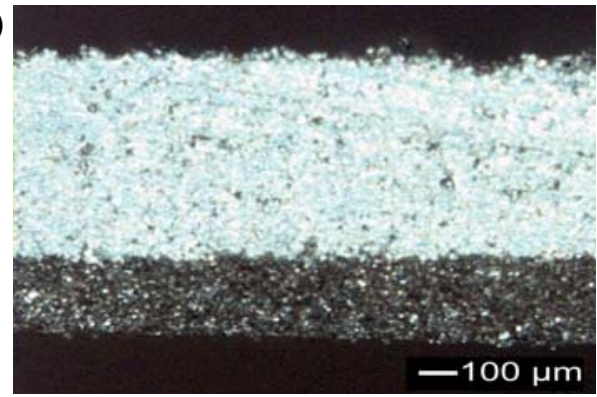

(b)

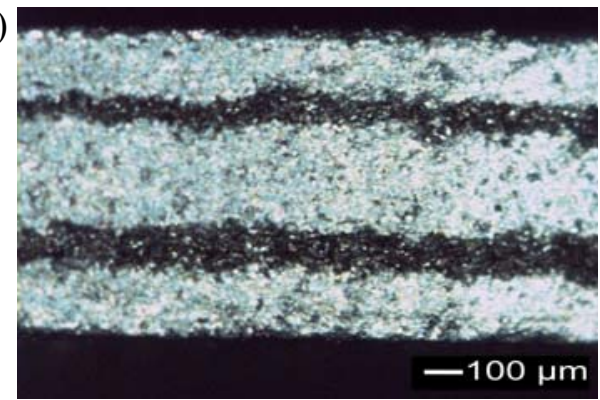

(c)

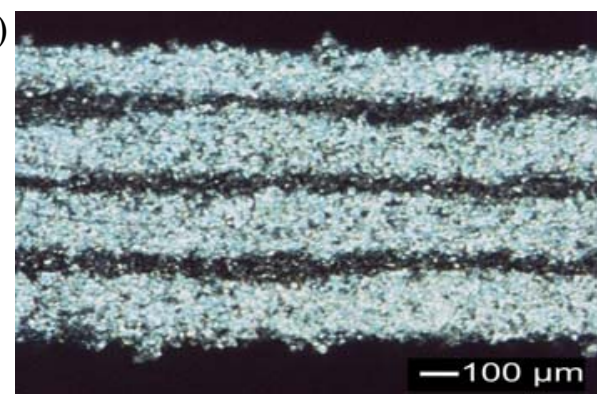

(d)

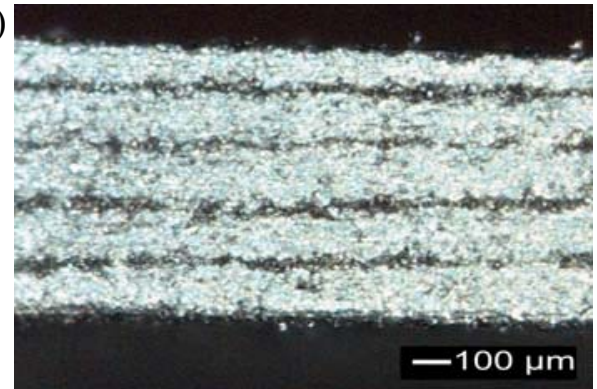

Fig. 6. Cross section images of multilayer samples $C / G=10 / 90$ using particle sized $25-32 \mu \mathrm{m}$ with the number of layer of a 2 ; b 5; c 7; and $\mathbf{d} 9$. The meaning of sample name of $\mathrm{C} / \mathrm{G}=10 / 90$ is given in Fig. 1 caption 


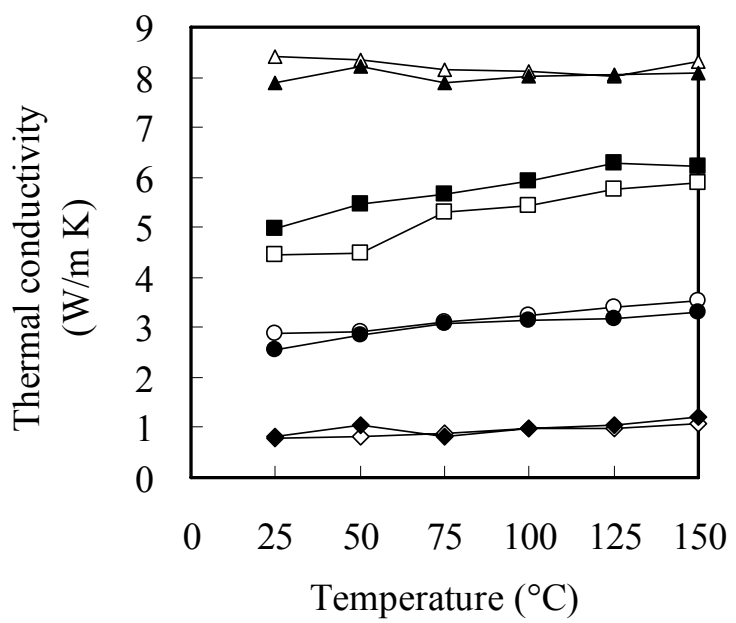

Fig. 7. Thermal conductivity in the vertical direction as a function of temperature. Samples used particle size of 25-32 $\mu \mathrm{m}$ : circles, $\mathrm{C} / \mathrm{G}=10 / 90$; triangles, SL graphite (G100); diamonds, SL carbonized wood (C100); except: squares, $\mathrm{C} / \mathrm{G}=10 / 90$ used particle size of $63-90 \mu \mathrm{m}$. Filled symbols, measurement in air; open symbols, measurement under vacuum conditions. The meaning of samples names is given in Fig. 1 caption 
(a)

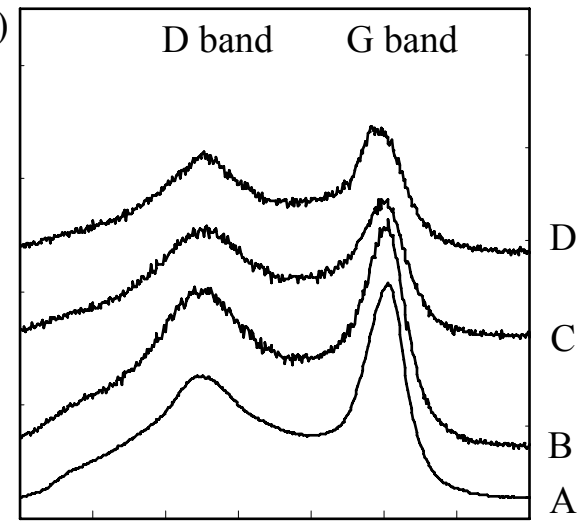

$\begin{array}{llllllll}1100 & 1200 & 1300 & 1400 & 1500 & 1600 & 1700 & 1800\end{array}$

Raman shift $\left(\mathrm{cm}^{-1}\right)$ (b)

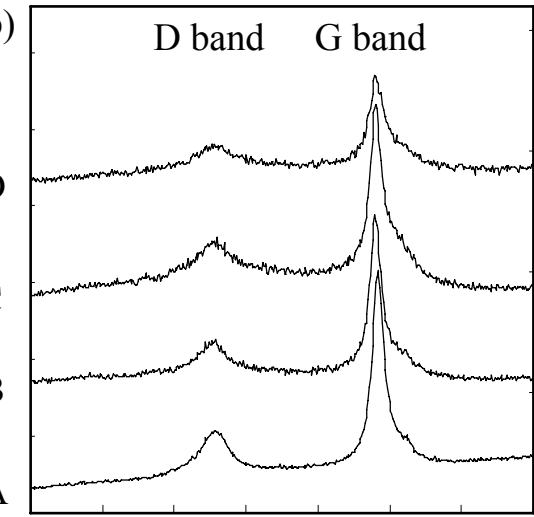

$\begin{array}{llllllll}1100 & 1200 & 1300 & 1400 & 1500 & 1600 & 1700 & 1800\end{array}$

Raman shift $\left(\mathrm{cm}^{-1}\right)$

Fig. 8. Raman spectra of a carbonized wood and $\mathbf{b}$ graphite. A, before heat treatment; B, heat treated particle size of $25-32 \mu \mathrm{m} ; \mathrm{C}$, that of 32-45 $\mu \mathrm{m}$; D, that of $63-90 \mu \mathrm{m}$. Heat treatment conditions: temperature of $700{ }^{\circ} \mathrm{C}$; heating rate of about $71{ }^{\circ} \mathrm{C} / \mathrm{min}$; holding time of $15 \mathrm{~min}$; pressure of $50 \mathrm{MPa}$; under vacuum 